Gut, 1982, 23, 410-414

\title{
Clostridium difficile toxin in acute diarrhoea complicating inflammatory bowel disease
}

\author{
M R B KEIGHLEY*, DENISE YOUNGS, MARGARET JOHNSON, \\ R N ALLAN, and D W BURDON
}

From The General Hospital, Birmingham

SUMmaRY The incidence of Clostridium difficile cytotoxin has been studied in 69 consecutive patients with inflammatory bowel disease complicated by severe diarrhoea or ileostomy flux during 74 admissions to hospital. The cytotoxin was identified in only four patients, all of whom had received antimicrobials. Clostridium difficile, but not cytotoxin, was identified in 10 of 43 admissions. This followed antimicrobial prophylaxis to cover a recent operation in two patients, and five were on long-term sulphasalazine. Only three patients with Clostridium difficile had not received an antimicrobial within one month of the study. Isolation of Clostridium difficile alone is of doubtful pathological significance, as it spontaneously disappeared without treatment in all patients.

It has been suggested that Clostridium difficile toxin may be responsible for relapse in patients with inflammatory bowel disease. ${ }^{12}$ Clostridium difficile toxin has also been implicated in the pathogenesis of antibiotic associated colitis. ${ }^{34}$ The organism is not generally found in the faeces of healthy adults, ${ }^{5}$ but is present in $40 \%{ }^{6}$ of normal neonates and the toxin is present in $14 \%$ of infants five months after birth. ${ }^{7}$ Clostridium difficile without toxin may be recovered from patients exposed to a variety of antimicrobials without any' evidence of colitis and occasionally without diarrhoea. ${ }^{8}$ Many of the patients in whom Clostridium difficile has been identified during a relapse of inflammatory bowel disease ${ }^{12}$ were receiving maintenance sulphasalazine or systemic antibiotics. The purpose of this study has been to document the incidence of Clostridium difficile toxin in patients with acute diarrhoea or ileostomy flux complicating inflammatory bowel disease and to observe the natural history of Clostridium difficile in inflammatory bowel disease.

\section{Methods}

\section{PATIENTS}

All patients admitted to a single unit with symptomatic relapse of inflammatory bowel disease

\footnotetext{
* Address for correspondence: M R B Keighley, The General Hospital, Steelhouse Lane, Birmingham B4 6NH.

Received for publication 14 September 1981
}

between November 1978 and August 1980 were studied. Relapse referred either to patients with severe systemic disease and acute diarrhoea leading to dehydration (irrespective of the site of disease or previous operation), or to patients with an ileostomy output greater than 1 litre per day. Sixty-nine patients were investigated during 74 hospital admissions (Table 1). The reasons for admission included acute proctocolitis in 24, acute diarrhoea complicating small bowel Crohn's disease in 19, ileostomy flux in 10 , and early postoperative diarrhoea or flux in 21 . The underlying diagnosis included ulcerative colitis in 21 . Crohn's disease was present in 48 patients three of whom also had an

Table 1 Comparison between phase 1 and phase 2 (patients)

\begin{tabular}{lll}
\hline & $\begin{array}{l}\text { Phase 1 (39) } \\
\text { Toxin }+C l \\
\text { difficile }\end{array}$ & $\begin{array}{l}\text { Phase 2 (30) } \\
\text { Toxin }\end{array}$ \\
\hline Age (yr) & 13 & \\
$20-40$ & 14 & 15 \\
$40-60$ & 12 & 9 \\
$\quad$ More than 60 & 14 & 6 \\
Medication & 17 & 9 \\
Steroids & & 11 \\
Sulphasalazine & 12 & 9 \\
Diagnosis & 27 & 21 \\
$\quad$ Ulcerative colitis & 1 & - \\
$\quad$ Crohn's disease & & \\
Other & & \\
\hline
\end{tabular}


associated carcinoma of the small (one) or large intestine (two) and four who had other disorders: diverticular disease (two), coeliac disease (one), and peptic ulcer (one). Maintenance treatment in these 68 patients included systemic corticosteroids in 23 patients and sulphasalazine in 28 . The mean age of the patients was $42 \cdot 3$ years (range: 21-91 years). One other patient had acute diarrhoea and appearances on sigmoidoscopy which suggested acute onset of inflammatory bowel disease, the subsequent course of this patient leaves us in no doubt, however, that she had pseudomembranous colitis.

\section{TECHNIQUES}

Stool specimens were collected during the acute illness for identification of Clostridium difficile cytotoxin. The toxin was demonstrated from serial dilutions of a faecal suspension placed on a mono layer of HeLa cells. ${ }^{9}$ If the toxin was present, there was rounding and clumping of cells which became separated from one another. This appearance was neutralised by Clostridium sordellii antitoxin. Clostridium difficile was isolated on lysed blood agar containing $70 \mathrm{mg} / \mathrm{l} \mathrm{kanamycin}$ and on $7 \%$ blood agar containing $500 \mathrm{mg} / \mathrm{l}$ cycloserine and $16 \mathrm{mg} / \mathrm{l}$ cefoxitin. Broth cultures of Clostridium difficile were tested for production of neutralised toxin on $\mathrm{HeLa}$ cells. Because of the work load in the laboratory, routine culture of stool specimens for Clostridium difficile was discontinued in January 1980. During the last eight months faecal samples were screened for presence of cytotoxin and examination for Clostridium difficile was undertaken only if toxin was identified. For clarity the two parts of the study will be referred to as phase 1 (toxin and organism) and phase 2 (toxin alone). The age, regular medical therapy, or diagnosis of patients in phase 1 or phase 2 is shown in Table 2.

\section{Results (Table 2)}

One patient (no. 1) was admitted with a one-month history of diarrhoea; she had previously received co-trimoxazole and the appearances on sigmoidoscopy suggested acute proctocolitis. A biopsy confirmed pseudomembranous colitis (Table 3 ) and Clostridium difficile and cytotoxin were found. Treatment with vancomycin eradicated the toxin and organism. The patient has had no further bowel symptoms during a follow-up of 18 months and we believe she was suffering from antibiotic associated colitis. This patients was excluded from subsequent analysis. Three patients (nos 2-4) acquired Clostridium difficile cytotoxin after an operation for Crohn's disease and in each case they had received antimicrobial prophylaxis. Two of these patients
Table 2 Details of admission samples with results

\begin{tabular}{|c|c|c|}
\hline Reason for admission & $\begin{array}{l}\text { Phase 1 } \\
\text { n:Toxin }+\mathrm{Cl} \text {. } \\
\text { difficile }\end{array}$ & $\begin{array}{l}\text { Phase } 2 \\
n: \text { Toxin (only } \\
\text { Cl. difficile } \\
\text { if toxin +ve) }\end{array}$ \\
\hline $\begin{array}{l}\text { Acute proctocolitis (24) } \\
\text { Acute diarrhoea (19) } \\
\text { Ileostomy flux (10) } \\
\text { Postoperative (21) }\end{array}$ & $\begin{array}{r}14: 1+7 \\
8: 0+2 \\
6: 0+0 \\
15: 3+5\end{array}$ & $\begin{array}{r}10: 0 \\
11: 0 \\
4: 0 \\
6: 0\end{array}$ \\
\hline Total & $43: 4+14$ & $31: 0$ \\
\hline $\begin{array}{l}\text { No antibiotics except } \\
\text { sulphasalazine (54) } \\
\text { Antibiotics within one } \\
\text { month of sample (20) }\end{array}$ & $\begin{array}{l}31: 0+8^{*} \\
12: 4+6\end{array}$ & $\begin{array}{r}23: 0 \\
8: 0\end{array}$ \\
\hline
\end{tabular}

* Five on sulphasalazine.

were treated immediately with vancomycin with elimination of the toxin and a rapid clinical response. The third patient was discharged from hospital before the result of the cytotoxin test was known: the patient continued to have diarrhoea, repeat faecal samples revealed persistent excretion of Clostridium difficile, and subsequent treatment with vancomycin resulted in rapid clinical improvement and disappearance of the organism.

In 10 other patients, Clostridium difficile alone was recovered from the stool. Broth cultures of these clostridia all produced cytotoxin. Two patients (nos 5, 6) had been treated previously by total colectomy and ileorectal anastomosis and had received prophylactic antimicrobials. The eight remaining patients (nos 7-14) had been admitted with acute disease: four had acute ulcerative colitis, two had acute Crohi.'s colitis, and two had small intestinal Crohn's disease. Five of these patients, however, were receiving sulphasalazine for colitis, thus leaving only three who had not been recently exposed to an antibiotic. None of the patients with Clostridium difficile alone received specific therapy. All of the patients were re-investigated four to six weeks later, but in none was Clostridium difficile subsequently found in the stool. One of the patients, however, later developed a relapse of ulcerative colitis requiring colectomy. Although faecal cultures were negative for Clostridium difficile, the organism was identified from the submucosa of the resected colon.

Of the 54 patients with acute inflammatory bowel disease who had not received an antibiotic, other than sulphasalazine, within one month of the study, none had evidence of Clostridium difficile toxin. Thirty-one of these patients were studied during phase 1 , and, of these, only eight (26\%) had Clostridium difficile in their faeces. 


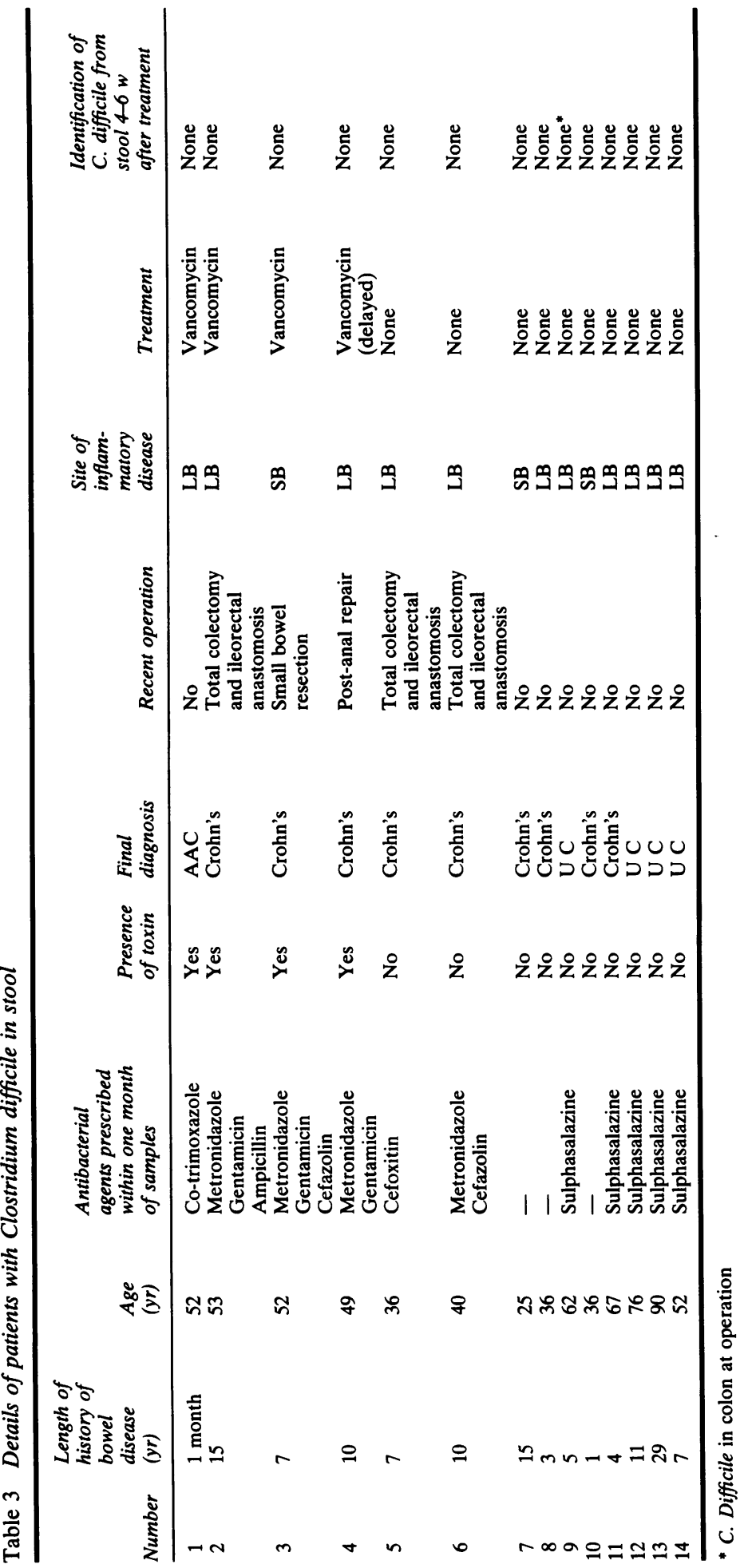




\section{Discussion}

This survey has shown that Clostridium difficile cytotoxin was identified in only four of the 74 episodes of severe diarrhoea complicating inflammatory bowel disease. This is in marked contrast with our experience in 88 patients with antibioticassociated colitis or diarrhoea, where cytotoxin was identified in $61(69 \%)$ and where Clostridium difficile alone was recovered in all of the remaining 27 cases $(31 \%) .{ }^{10}$ One patient in this study was subsequently shown to have had antibioticassociated colitis. The other three patients had undergone recent surgical treatment with antimicrobial prophylaxis. These patients did not differ clinically from many of the patients observed in this hospital who have had postoperative antibioticassociated colitis. ${ }^{9}$ None of the patients had a rectal biopsy during the episode of diarrhoea, principally because of their underlying disease. Nevertheless, the manifestations of their disease and the rapid response to vancomycin ${ }^{11}$ suggests that these patients had had a mild episode of antibioticassociated colitis rather than intestinal colonisation by Clostridium difficile as a complication of their inflammatory disease. There were two other patients in whom the organism was recovered alone without cytotoxin after exposure to prophylactic antimicrobials given during colectomy and ileorectal anastomosis. The role of Clostridium difficile in causing the diarrhoea of these patients is uncertain. In our experience there are a small number of patients who have sigmoidoscopic or histological evidence of pseudomembranous colitis ${ }^{12}$ in whom the organism is found in the absence of cytotoxin ${ }^{13}$ and we believe that these two patients may have been in this category. Furthermore, in untreated patients the presence of toxin may be transient and often disappears despite persistent excretion of Clostridium difficile. It is possible that the absence of toxin might be due to insufficient numbers of clostridia to produce a measurable level of cytotoxin or to production of only small amounts of toxin by the clostridia. Clostridium difficile but not cytotoxin was found in single stool specimens from the remaining eight patients. This probably represents colonisation by the organism but our data do not establish whether this coincided with the onset of relapse, particularly as repeated stool specimens were not cultured. These patients had not had an operation or been exposed to antimicrobials other than sulphasalazine, which was being used as maintenance therapy for ulcerative colitis or Crohn's disease. It is interesting that Clostridium difficile disappeared without treatment even though sulphasalazine treatment was continued. We believe that colonisation of the colon by Clostridium difficile may occur more readily when the normal intestinal flora is disturbed. In hamsters colonisation by Clostridium difficile is associated with a reduction in the counts of anaerobic streptococci and corynebacteria.$^{14} \mathrm{~A}$ fall in the counts of Bacteroides sp has also been observed when oral kanamycin or neomycin and metronidazole is used for bowel preparation, ${ }^{15}$ a regime which has been associated with antibiotic-associated colitis. ${ }^{16}$ The intestinal microflora is also abnormal with low anaerobic counts in patients with inflammatory bowel disease. ${ }^{17}$ We believe that such conditions favour the identification of Clostridium difficile and that their presence should not necessarily be regarded as pathological. Indeed, in all such patients seen in this survey the organisms spontaneously disappeared within six weeks without treatment. Sulphasalazine may be associated with an alteration of the normal faecal microflora ${ }^{18}$ which may also predispose these patients to colonisation by Clostridium difficile. We would conclude therefore that Clostridium difficile toxin is rare in patients with inflammatory bowel disease unless the patient has been exposed to antibiotics and the isolation of this organism is therefore of doubtful pathological significance.

\section{References}

1 LaMont, JT, Trnka YM. Therapeutic implications of Clostridium difficile toxin during relapse of chronic inflammatory bowel disease. Lancet 1980; 1: 381-3.

2 Bolton RP, Sherriff RJ, Read AE. Clostridium difficile associated diarrhoea: a role in inflammatory bowel disease. Lancet 1980; 1: 383-4.

3 Larson HE, Price AB, Honour P, Borriello SP. Clostridium difficile and the aetiology of pseudomembranous colitis. Lancet 1978; 1: 1063-6.

4 Bartlett JG, Chang TW, Gurwith M, Gorbach SL, Onderdonk AB. Antibiotic associated pseudomembranous colitis, due to toxin producing clostridia. N Engl J Med 1978; 298: 531-4.

5 Larson HE. Pseudomembranous colitis is an infection. J Infection. 1979; 1: 221-6.

6 George WL, Sutter VL, Finegold SM. Antimicrobial agent induced diarrhoea - a bacterial disease. $J$ Infect Dis 1977; 136: 822-8.

7 Rietra PJGM, Slaterus KW, Zanen HC, Menwissen SGM. Clostridial toxin in faeces of healthy infants. Lancet 1978; 2: 319.

8 Lishman AH, Al Jumaili IJ, Record CO. Spectrum of antibiotic-associated diarrhoea. Gut 1981; 22: 34-7.

9 Keighley MRB, Burdon DW, Alexander-Williams J, Shinagawa N, Arabi Y, Thompson H, Youngs D, Bentley S, George RH. Diarrhoea and pseudomembranous colitis after gastrointestinal operations. 
Lancet 1978; 2: 1165-7.

10 Burdon DW, Keighley MRB, Allan RN, George RH. Clostridial toxin in inflammatory bowel disease. Lancet 1980; 1: 1421-2.

11 Keighley MRB, Burdon DW, Arabi Y, AlexanderWilliams $J$, Thompson $H$, Youngs $D$, Johnson $M$, Bentley S, George RH, Mogg GAG. Randomised controlled trial of vancomycin for pseudomembranous colitis and postoperative diarrhoea. $\mathrm{Br} \operatorname{Med} J$ 1978; 2: 1667-9.

12 Price AB, Davies DR. Pseudomembranous colitis. J Clin Path 1977; 30: 1-12.

13 Mogg GAG, Keighley MRB, Burdon DW, AlexanderWilliams J, Youngs D, Johnson M, Bentley S, George RH. Antibiotic associated colitis - a review of 66 cases. Br J Surg 1979; 66: 738-42.

14 Lusk RH, Tekety R, Silva J, Browne RA, Ringler DH,
Abrams GD. Clindamycin induced enterocolitis in hamsters. J Infect Dis 1978; 137: 464-75.

15 Arabi Y, Dimock F, Burdon DW, Alexander-Williams J, Keighley MRB. Influence of bowel preparation and antimicrobials on colonic microflora. Br J Surg 1978; 65: 555-9.

16 Keighley MRB, Arabi Y, Alexander-Williams J, Youngs D, Burdon DW. Comparison between systemic and oral antimicrobial prophylaxis in colorectal surgery. Lancet 1979; 1: 894-7.

17 Krook A, Danielsson D, Kyellander J, Janerot G. Changes in the faecal flora of patients with Crohn's disease during treatment with metronidazole. Scand J Gastroenterol 1979; 14: 705-10.

18 Krook A. Microbiological and clinical studies on Crohn's disease. Sweden: Thesis University of Uppsala, 1980. 